\title{
G7 Ülkelerinde Ticari Dışa Açıklık, Finansal Açıklık ve Ekonomik Büyüme İlişkisi
}

\author{
The Relationship Between Trade Openness, Financial Openness and Economic \\ Growth in 67 Countries
}

Yusuf DEMIR *

\begin{abstract}
$\ddot{O} Z$
Dışa açıklık, ticari ve finansal açıklık olarak incelenmektedir. Bir ülkenin ticari ve finansal olarak dışa açık olup olmaması, ülke içerisinde uyguladı̆̆ ekonomi politikalarının diğer ülkelerle ne derecede uyumlu olduğunu ölçmeye yarayan bir araçtır. Ülkelerin neden ticari ve finansal liberalizasyona ihtiyaç duydukları, ticari ve finansal açıklığın büyüme üzerine etkileri ile açıllanabilir. Bu çalışmanın amacı da, G7 ülkeleri olarak bilinen, Kanada, Almanya, Fransa, Ingiltere, Italya, Japonya ve Amerika Birleşik Devletleri'ne ait, son 50 yılda, 1970-2020, ticari ve finansal açıklı göstergelerinin ekonomik büyüme üzerindeki etkisinin araştırllmasıdır. Panel veri analizi ile yapılan incelemeler sonucunda, ticari ve finansal dışa açıklı̆̆ı ekonomik büyümede meydana gelen değişimleri açılkladıkları, ticari ve finansal dışa açıklıktaki bir artışın büyümede de bir artışa yol açtı̆̆ı görülmüşsürr.
\end{abstract}

ANAHTAR KELIMELER

Ticari Dışa Açıklık, Finansal Açılklı, Büyüme

\begin{abstract}
Openness is examined as trade openness and financial openness. Whether a country is open to foreign markets in terms of trade and financial means that the government has a tool to measure to what extent the economic policies implemented within the country are compatible with other countries. Why countries need commercial and financial liberalization can be explained by the effects of trade and financial openness on growth. This study investigates the impact of commercial and financial openness indicators of Canada, Germany, France, England, Italy, Japan, and the United States of America, known as the $G 7$ countries, on economic growth in the last 50 years (1970-2020). As a result of the analyzes made with panel data analysis, it is seen that trade and financial openness explained the changes in economic growth, and an increase in trade and financial openness led to the rise in growth.
\end{abstract}

\section{KEYWORDS}

Trade Openness, Financial Openness, Growth

\begin{tabular}{|c|c|c|}
\hline \multicolumn{2}{|c|}{ Makale Geliş Tarihi / Submission Date } \\
08.01.2021
\end{tabular}

\footnotetext{
* Sivas Cumhuriyet Üniversitesi İktisadi ve İdari Bilimler Fakültesi, ydemir@cumhuriyet.edu.tr, ORCID: 0000-0001-5677-8709
} 


\section{GİRIŞ}

Küreselleşme, köken olarak, genel manada ekonomi ve dünyayı kapsayan, ekonomiyle alakalı bağlantılar olarak değerlendirilir ve ülkelerin ekonomik açıdan karşılıklı bağımlılıkları ile ilgilidir (Giddens, 2000:41-42). Bir ülkenin küreselleşme seviyesinin ve/veya ekonomik açıdan dünyaya entegrasyonunun belirlenmesinde, ticari ve finansal dışa açıklık göstergeleri baz alınır (Saçık, 2009:527). Şöyle ki, finansal ve ticari dışa açıklık, temel olarak bir ülkenin finansal ve/veya ticari serbestliğin seviyesini ölçmek için kullanılır. Finansal ve ticari açıklık; mal, hizmet, işgücü ve sermayenin ülkeler arasında engellerle, kısıtlamalarla yüz yüze gelmeden, serbest bir şekilde hareket edebilmesidir (Yapraklı 2007:68). Küreselleşmeyle beraber bir ülkenin dünyaya ne ölçüde entegre olduğunu, içeriye veya dışarıya yönelik ekonomi politikalarından hangisini daha çok uyguladığını belirlemek amacı ile dışa açıklık kavramı kullanılır. Dışa açık ekonomi politikası uygulamak, ticari ve finansal politikaları liberalize etmek ile mümkündür (Saçık, 2009:527). Ticari dışa açıklık, malların ve hizmetlerin ticaretindeki devlet kontrollerinin kaldırılmasıyla uluslararası serbest ticaretin sağlana bilmesini amaçlarken; finansal dı̧̧a açıklık ilk olarak yurt içi bankacılık ve diğer finansal araçlar üzerinde devletin müdahalesi ile kontrollerini kaldırmayı hedefleyen ve akabinde yurtiçi finansal piyasalar ile uluslararası piyasaların bütünleşmesini öngörür (Dağdelen, 2004:5-6).

Dışa açıklık ekonomik büyüme arasındaki ilişki, ekonomik ve finansal kanallar ile gerçekleşmektedir. Ticari dışa açıklık, ihracatı artırır, artan ihracat da ülkenin sahip olduğu dövizleri rezervlerini artırır. Öte taraftan, yurtiçinde üretilemeyen hammadde girdileri ve sermaye malı dış alımı yoluyla da milli gelirin artmasını sağlar. Bu da hem tasarruf-yatırım hem de dış ticaret açığı sorunu ortadan kaldırır. Ticari dışa açıklık, dünya ile bütünleşen ülkelerin mallarına ait oluşan talebi karşılayacak teknolojik gelişmeyi sağlamakta ve bu yolla da üretim imkânlarını artırmaktadır (Yapraklı, 2007:68-69).

Finansal açıklık ve ekonomik büyüme arasındaki ilişki ise, genel kanı bakımından iki yönlüdür. Birincisi, öncülüğünü McKinnon (1973) ve Shaw (1973) tarafından birbirlerinden bağımsız olarak yapılan çalışmalara dayanan görüş olan finansal serbestleşme politikalarının ekonomik büyümeye olumlu etki yaptığıdır. Finansal serbestleşme politikaları ile, ekonomide finansal araç çeşitliliği, tasarruf ve yatırımlar artırarak ekonominin büyümesine katkı sağlanır (Danışoğlu 2004:21). Derinliği yüksek olan finansal piyasalarda sabit sermaye yatırımları ve bunun sonucunda da ekonomik büyüme artar. Bu da riski düşük, karı yüksek yatırımların finansmanını kolaylaştırır ve verimliliği artıır, verimliliğin artması yüksek büyümeyi de beraberinde getirir. Íkincisi, mali ve finansal açıdan yeterli derinliği bulunmayan gelişmekte olan ülkelerde finansal serbestleşmenin kontrolsüz bir şeklide uygulanması ekonomiyi krizlere daha açık hale getirir. Sermaye de, daha serbest hale gelen gelişmekte olan ülkelerde daha yüksek kazanca kavuşacağından, yatırımcılar bu ülkelere yönelmektedir. Bu da finansal serbestleşmenin gelişmekte olan ülkelere kısa vadeli portföy yatırımı olarak döner. Ancak bu durum, ali ve finansal açından derinliği düşük ülkeleri, daha kırılgan yapar. Özellikle siyasi riskleri olan gelişmekte olan ülkelerde ani ve büyük miktarda fon çıkışları finansal krizleri de beraberinde getirir (Korkmaz vd., 2010:2821-2822). Finansal açıklık ve ekonomik büyüme arasına, ekonomik dinamizmi arttırması, ülkedeki rekabet yapısını iyileştirmesi, ülkeler arası teknoloji ve bilgi transferini kolaylaştırması ve dünya kaynak dağılımında optimizasyonu gerçekleştirmesi açısından olumlu sonuçları olsa da; ulusal ekonomi politikalarının sınırlandırılması, bebek sanayinin korunamaması ve tekelleşme tehlikesi ile ekonomik kırılganlığın artması gibi olumsuz sonuçlara da yol açabilmektedir (Özyıldız ve Dineri, 2020:33). 


\section{Şekil 1: Dışa Açıklık ile Ekonomik ve Finansal Gelişme Arasındaki İlişki}



Kaynak: Lu, D. ve Liu, E. (2020). In Search of Currency Internationalisation: A Perspective from Financial Openness, Economic and Political Studies, 8(3), 314.

Finansal açıklık ve ekonomik büyüme ile ticari dışa açıklık ve ekonomik büyüme arasında, farklı görüşlere rağmen, ağır basan sonuç, bu değişkeler arasındaki etkileşim olumlu yöndedir; finansal açıklığın ve ticari dışa açıklığın ekonomik büyüme üzerinde olumlu etkisi vardır. Bu etki Şekil 1'de gösterilmeye çalışılmıştır. Buna göre, dışa açıklık, ekonomik kanal ile sermaye dağılımı, risk paylaşımı ve finansal kanal ile ise likidite, etkinlik, istikrar üzerinden ekonomik ve finansal gelişmeye yol açmaktadır (Lu ve Liu, 2020:313). Bu çalışmanın kaygısı da, G7 ülkeleri olarak bilinen, Kanada, Almanya, Fransa, İngiltere, İtalya, Japonya ve Amerika Birleşik Devletleri'ne ait, ticari dışa açıklık ve finansal açıklık açıklayıcı değişkelerinin, son 50 yılda, 1970-2020, bu ülkelerin açıklanan değişkeni olan büyümeleri üzerinde etkili olup olmadıklarının araştırılmasıdır.

\section{LITERATÜR ÖZETI}

Ticari ve finansal açıklığın, ister ayrı ayrı ister birlikte, büyümeye olan etkilerini araştırmak amacı ile birçok çalı̧̧ma yapılmıştır. Ticari dışa açıklık ile büyüme konusunu araştırmalar 1960'tan bu yana, finansal açıklık ve büyüme konusunu araştırmalar ise 1990'dan bu yana yoğunlaşsa da tam bir görüş birliğinden bahsetmek mümkün gözükmemektedir. Finansal ve ticari açıklık ile büyümeyi arasındaki ilişkiyi araştıran çalışmaların bazılarının sonucu pozitif ilişkiyi gösterirken, diğer bazı çalışmaların sonuçları ise negatif ilişkiyi göstermektedir. Diğer, bazı çalışmalar ise finansal ve ticari dışa açıklık ile büyüme arasında ilişkili bulunamamıştır (Çeştepe vd., 2018:5-6).

Tablo 1: İlgili Literatür

\begin{tabular}{|c|c|c|c|c|c|}
\hline Yazar/Yıl & Dönem & Ülke(ler) & Yöntem & Değişkenler & Sonuç \\
\hline $\begin{array}{l}\text { Ericsson ve } \\
\text { Irandoust, } \\
2001\end{array}$ & 1970-1997 & $\begin{array}{l}\text { Danimarka, } \\
\text { Finlandiya, } \\
\text { Norveç, } \\
\text { İsveç }\end{array}$ & $\begin{array}{l}\text { Lag- } \\
\text { augmented } \\
\text { Oto } \\
\text { Regresyon }\end{array}$ & $\begin{array}{l}\text { DYSY'ler ile } \\
\text { ekonomik } \\
\text { büyüme }\end{array}$ & $\begin{array}{l}\text { İsveç için DYSY'lerden } \\
\text { büyümeye doğru tek } \\
\text { yönlü, Norveç için çift } \\
\text { yönlü nedensellik varken, } \\
\text { Finlandiya ve Danimarka } \\
\text { için nedensellik yoktur. }\end{array}$ \\
\hline $\begin{array}{l}\text { Tornell, } \\
\text { Westermann } \\
\text { ve Martinez, } \\
2004\end{array}$ & 1980- 1999 & 52 Ülke & $\begin{array}{l}\text { Panel } \\
\text { Regresyon } \\
\text { Analizi }\end{array}$ & $\begin{array}{l}\text { Finansal } \\
\text { serbestleşme, } \\
\text { kredi } \\
\text { büyümesi, } \\
\text { GSYH }\end{array}$ & $\begin{array}{l}\text { Finansal serbestleşme, } \\
\text { hem ticari serbestleşmeye } \\
\text { hem de, finansal } \\
\text { kırılganlığa sebep olur. }\end{array}$ \\
\hline
\end{tabular}




\begin{tabular}{|c|c|c|c|c|c|}
\hline $\begin{array}{l}\text { Lee ve Shin, } \\
2008\end{array}$ & 1980-1999 & 58 ülke & $\begin{array}{l}\text { Panel Veri } \\
\text { Analizi }\end{array}$ & $\begin{array}{l}\text { Serbestleşme } \\
\text { ve ekonomik } \\
\text { büyüme }\end{array}$ & $\begin{array}{l}\text { Finansal serbestleşmenin } \\
\text { büyüme üzerinde pozitif } \\
\text { etkisi vardır }\end{array}$ \\
\hline $\begin{array}{l}\text { Bader ve } \\
\text { Qarn, } \\
2008\end{array}$ & $1960-2004$ & $\begin{array}{l}\text { Cezayir, } \\
\text { Misir, İsrail, } \\
\text { Fas, Suriye } \\
\text { ve Tunus }\end{array}$ & $\begin{array}{l}\text { Toda- } \\
\text { Yamamoto } \\
\text { nedensellik }\end{array}$ & $\begin{array}{l}\text { Finansal } \\
\text { kalkınma ile } \\
\text { ekonomik } \\
\text { büyüme }\end{array}$ & $\begin{array}{l}\text { Genel olarak, finansal } \\
\text { kalkınma ve ekonomik } \\
\text { büyümeye, arasında çift } \\
\text { yönlü nedensellik vardır } \\
\end{array}$ \\
\hline $\begin{array}{l}\text { Chang, } \\
\text { Kaltani ve } \\
\text { Loayza, } 2009\end{array}$ & $1960-2000$ & 82 ülke & GMM & $\begin{array}{l}\text { GSYH ve } \\
\text { ticari açıklık }\end{array}$ & $\begin{array}{l}\text { Ticari dışa açıklık } \\
\text { büyümeyle ilişkilidir ve } \\
\text { reformlar daha hızlı } \\
\text { büyümeye yol açar }\end{array}$ \\
\hline $\begin{array}{l}\text { Gries ve } \\
\text { Redlin, } \\
2012\end{array}$ & $1970-2009$ & 158 ülke & $\begin{array}{l}\text { Panel eş- } \\
\text { bütünleşme }\end{array}$ & $\begin{array}{l}\text { Ticari açıklık } \\
\text { ve GSYH }\end{array}$ & $\begin{array}{l}\text { Ticari açıklık ile büyüme } \\
\text { arasında uzun dönemde } \\
\text { nedensellik çift yönlüdür }\end{array}$ \\
\hline $\begin{array}{l}\text { Chang ve } \\
\text { Mendy, } \\
2012\end{array}$ & 1980-2009 & $\begin{array}{l}\text { 39 Afrika } \\
\text { Ülkesi }\end{array}$ & $\begin{array}{l}\text { Panel } \\
\text { Regresyon } \\
\text { Analizi }\end{array}$ & $\begin{array}{l}\text { Ticari açıklık, } \\
\text { yatırımlar ve } \\
\text { GSYH }\end{array}$ & $\begin{array}{l}\text { Ticari açıklık büyümeyi } \\
\text { pozitif yönde etkiler. }\end{array}$ \\
\hline $\begin{array}{l}\text { Zeren ve Ari, } \\
2013\end{array}$ & $1970-2011$ & G7 Ülkeleri & $\begin{array}{l}\text { Panel } \\
\text { Granger } \\
\text { Nedensellik } \\
\text { Testi }\end{array}$ & $\begin{array}{l}\text { Ticari açıklık } \\
\text { ve GSYH }\end{array}$ & $\begin{array}{l}\text { Hem ticari açıklıktan } \\
\text { büyümeye hem de } \\
\text { büyümeden ticari açıklığa } \\
\text { çift yönlü pozitif ilişki } \\
\text { vardır }\end{array}$ \\
\hline $\begin{array}{l}\text { Bourdon, } \\
\text { Mauel ve } \\
\text { Vijil, } \\
2013\end{array}$ & $1995-2009$ & 157 Ülke & $\begin{array}{l}\text { Dinamik } \\
\text { Panel } \\
\text { Analizi }\end{array}$ & $\begin{array}{l}\text { Ticari açıklık } \\
\text { ve GSYH }\end{array}$ & $\begin{array}{l}\text { İhracat çeşitlendikçe ticari } \\
\text { dişa açılık ekonomik } \\
\text { büyümeyi negatif yönde } \\
\text { etkiler }\end{array}$ \\
\hline $\begin{array}{l}\text { Kennedy, } \\
2013\end{array}$ & $2000-2010$ & $\begin{array}{l}34 \text { ülke } \\
\text { gelişmiş } \\
\text { ülke }\end{array}$ & $\begin{array}{l}\text { Panel Veri } \\
\text { Analizi }\end{array}$ & $\begin{array}{l}\text { GSYH ve } \\
\text { finansal } \\
\text { açıklık }\end{array}$ & $\begin{array}{l}\text { Finansal açıklık ekonomik } \\
\text { büyümeyi pozitif yönde } \\
\text { etkilemektedir. }\end{array}$ \\
\hline $\begin{array}{l}\text { Dao, } \\
2014\end{array}$ & $1980-2010$ & 71 Ülke & $\begin{array}{l}\text { Panel Veri } \\
\text { Analizi }\end{array}$ & $\begin{array}{l}\text { GSYH ve } \\
\text { ticari açıklık }\end{array}$ & $\begin{array}{l}\text { Ticari açıklık büyümeyi } \\
\text { pozitif yönde etkiler. }\end{array}$ \\
\hline $\begin{array}{l}\text { Abbes ve vd., } \\
2015\end{array}$ & $1980-2010$ & 65 ülke & $\begin{array}{l}\text { Panel } \\
\text { nedensellik }\end{array}$ & $\begin{array}{l}\text { Doğrudan } \\
\text { sermaye } \\
\text { yatırımları ve } \\
\text { ekonomik } \\
\text { büyümeye }\end{array}$ & $\begin{array}{l}\text { Sermaye yatırımlarından } \\
\text { ekonomik büyümeye } \\
\text { doğru bazı ülkelerde tek } \\
\text { yönlü, bazılarında ise çift } \\
\text { yönlü nedensellik vardır. }\end{array}$ \\
\hline $\begin{array}{l}\text { Idris, Yusop } \\
\text { ve Habibullah, } \\
2016\end{array}$ & $1977-2011$ & $\begin{array}{l}87 \text { gelişmiş } \\
\text { ülke }\end{array}$ & $\begin{array}{l}\text { Dinamik } \\
\text { Panel } \\
\text { Analizi }\end{array}$ & $\begin{array}{l}\text { GSYH ve } \\
\text { ticari açıklık }\end{array}$ & $\begin{array}{l}\text { Ticari dışa açıklık, } \\
\text { ekonomik büyümeyi } \\
\text { pozitif olarak etkiler }\end{array}$ \\
\hline $\begin{array}{l}\text { Silajdzic ve } \\
\text { Mehic, } \\
2017\end{array}$ & $1992-2014$ & $\begin{array}{l}\text { AB geçiş } \\
\text { ülkeleri }\end{array}$ & CCE & $\begin{array}{l}\text { Ticari açıklık } \\
\text { ve GSYH }\end{array}$ & $\begin{array}{l}\text { Ticari dışa açıklık, } \\
\text { büyümede teknoloji yoğun } \\
\text { üretim yapan ülkeler için } \\
\text { pozitiftir }\end{array}$ \\
\hline
\end{tabular}

\section{VERİ SETİ, YÖNTEM VE BULGULAR}

Ticari dışa açıklık ve finansal dışa açıklık ve büyüme arasındaki ilişkinin araştırıldığı bu çalışmada Aizenman (2008) ve Ümit (2016)'nın çalışmaları referans alınarak oluşturulan regresyon modeli şu şeklidedir:

$$
\mathrm{GDP}_{\mathrm{it}}=\beta_{0}+\beta_{1} \mathrm{TO}_{\mathrm{it}}+\beta_{2} \mathrm{FO}_{\mathrm{it}}+\mathrm{U}_{\mathrm{it}}
$$

Dünya Bankası veri tabanından elde edilen değerleri doğal logaritmaları alınarak (üssel artışlardan aritmetik artışlara dönüştürmek amacıyla) kullanılacak bu modeldeki değişkenler; GDP büyüme, TO, ticari dışa açıklık göstergesi [(ihracat + ithalat)/GDP*100] ve FO, finansal aç1klık göstergesi [(net uluslararası sermaye girişi + net uluslararası sermaye çıkışı)/GDP*100] şeklindedir. G7 ülkeleri, Kanada, Almanya, Fransa, İngiltere, İtalya, Japonya ve Amerika Birleşik Devletleri’ne ait, 1970-2020 dönemi için yıllık veriler üzerinden panel veri analizi yapılmaktadır. Tablo 1'de değişkenlere ait tanımlayıcı istatistikler gösterilmektedir. 
Tablo 2: Değişkenlerin Tanımlayıcı İstatistikleri

\begin{tabular}{|c|c|c|c|c|c|c|c|}
\hline & Ortalama & Medyan & Maksimum & Minimum & Standart Sapma & Çarpıklık & Basıklık \\
\hline \multicolumn{8}{|c|}{ GDP } \\
\hline $\mathrm{ABD}$ & 29.339 & 29.463 & 30.491 & 27.639 & 0.841 & -0.457 & 2.030 \\
\hline Almanya & 27.923 & 28.169 & 28.836 & 26.106 & 0.762 & -0.660 & 2.309 \\
\hline Fransa & 27.596 & 27.799 & 28.539 & 25.705 & 0.784 & -0.652 & 2.407 \\
\hline İngiltere & 27.532 & 27.699 & 28.604 & 25.671 & 0.893 & -0.557 & 2.048 \\
\hline İtalya & 27.345 & 27.625 & 28.314 & 25.439 & 0.833 & -0.753 & 2.339 \\
\hline Japonya & 28.342 & 28.831 & 29.225 & 26.010 & 0.886 & -1.090 & 2.938 \\
\hline Kanada & 26.888 & 26.918 & 28.039 & 25.135 & 0.827 & -0.292 & 2.121 \\
\hline Tümü & 27.852 & 27.907 & 30.491 & 25.135 & 1.108 & -0.008 & 2.713 \\
\hline \multicolumn{8}{|c|}{ TO } \\
\hline $\mathrm{ABD}$ & 3.215 & 3.240 & 3.585 & 2.519 & 0.250 & -0.707 & 3.406 \\
\hline Almanya & 4.141 & 4.018 & 4.655 & 3.565 & 0.335 & 0.179 & 1.758 \\
\hline Fransa & 4.016 & 3.999 & 4.344 & 3.595 & 0.185 & -0.165 & 2.417 \\
\hline İngiltere & 4.099 & 4.093 & 4.320 & 3.777 & 0.118 & -0.282 & 3.561 \\
\hline İtalya & 3.954 & 3.948 & 4.282 & 3.523 & 0.193 & -0.117 & 2.248 \\
\hline Japonya & 3.369 & 3.361 & 3.842 & 3.007 & 0.250 & 0.311 & 1.874 \\
\hline Kanada & 4.280 & 4.296 & 4.633 & 3.895 & 0.191 & -0.085 & 2.080 \\
\hline Tümü & 3.868 & 3.968 & 4.655 & 2.519 & 0.440 & -0.572 & 2.671 \\
\hline \multicolumn{8}{|c|}{ FO } \\
\hline ABD & 0.794 & 0.952 & 1.964 & -0.996 & 0.780 & -0.352 & 1.992 \\
\hline Almanya & 0.832 & 0.568 & 3.072 & -0.726 & 1.057 & 0.159 & 1.712 \\
\hline Fransa & 1.061 & 1.300 & 2.906 & -0.513 & 0.941 & -0.052 & 1.848 \\
\hline İngiltere & 1.758 & 1.633 & 3.462 & -0.494 & 0.803 & 0.022 & 3.192 \\
\hline İtalya & 0.148 & 0.140 & 2.303 & -1.981 & 0.909 & 0.127 & 2.829 \\
\hline Japonya & 0.021 & 0.053 & 1.705 & -1.290 & 0.870 & 0.280 & 1.982 \\
\hline Kanada & 1.574 & 1.530 & 2.953 & -0.007 & 0.638 & -0.024 & 2.584 \\
\hline Tümü & 0.884 & 0.987 & 3.462 & -1.981 & 1.050 & -0.109 & 2.326 \\
\hline
\end{tabular}

Tablo 1'e göre, G7 ülkeleri içerisinde incelenen dönemde en yüksek GDP ABD'de, en düşük ise Kanada'dadır. En yükssek ticari dış açıklık Almanya'da, en düşük ise, ABD'de, en yüksek finansal dış açıklık İngiltere'de, en düşük İtalya'dadır. Başka bir ifade ile en fazla dışa açık olan ülke ticari açıdan Almanya, finansal açıdan ise İngiltere olmuştur. Genellikle küçük standart sapma değeri, ortalamadan sapmaların küçük olduğunu göstermektedir. Tersi durumda yani büyük standart sapma söz konusu olduğunda ise, verilerin ortalamadan uzaklaştığı anlaşılmaktadır. GDP'de İngiltere, TO'da ve FO'da ise Almanya, en büyük standart sapmaya sahip olan ülkelerdir.

Şekil 2'de G7 ülkelerinin GDP'lerinin zaman yolu gösterilmiştir. Genel olarak bakıldığında bütün ülkelerin GDP'leri son 50 yılda belirgin şekilde artış göstermiştir. En istikrarlı artışı, ABD ve Kanada yaşamıştır. Avrupa ülkeleri olan Almanya, Fransa, İngiltere ve İtalya'nın dip ve zirve noktalarını yaşadıkları yıllar benzerlik göstermektedir. Bu bize, hem üretimin bollaşmasının hem de kitlaşmasının ülkeler arasında bulaşıcı olduğunu, ülkelerin birbirlerini etkilediklerini göstermektedir. Şekil 3'te ticari dışa açıklığının zaman yolu gösterilmiştir. $\mathrm{Bu}$ değişken bütün ülkelerde inişli çıkışlı bir seyir izlemiştir. Ülkelerin zirve ve dip yaptı̆̆ yıllar genelde örtüşmemektedir. En istikrarsız ülke olarak Japonya dikkat çekmektedir. Genel olarak incelenen dönemde ülkelerin ticari dışa açılmalarının, inişli çıkışlı olsa da, artığını söyleyebiliriz. Şekil 4'te G7 ülkelerinin finansal dışa açıklık değişkeninin zaman yolu gösterilmiştir. Bu değişken de ticari dişa açıklık değişkeninde olduğu gibi bütün ülkelerde inişli çıkışlı bir seyir izlemiştir; fakat keskin dip ve keskin zirve noktalar belirgindir. 


\section{Şekil 2: Ülkelerin Büyümesi}

\section{LOGGDP}

Kanada

Almanya

Fransa


Italya

Japonya

$A B D$
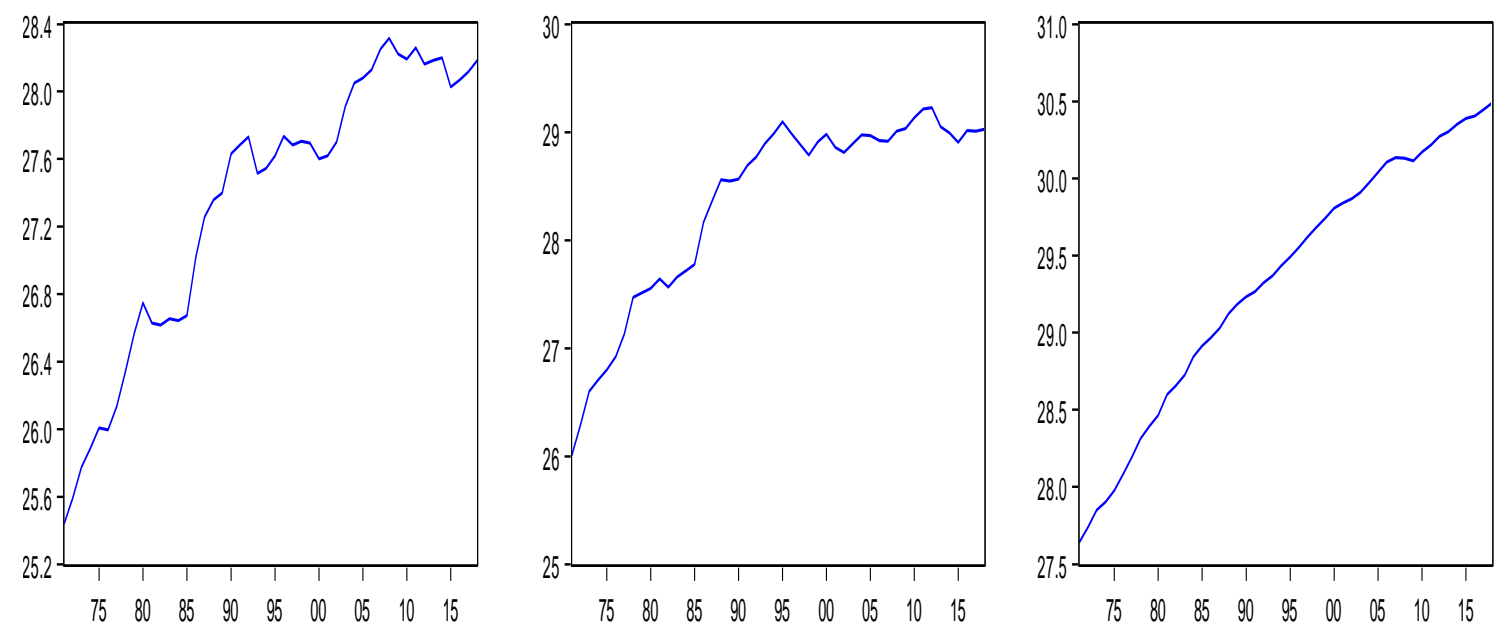

Ingiltere

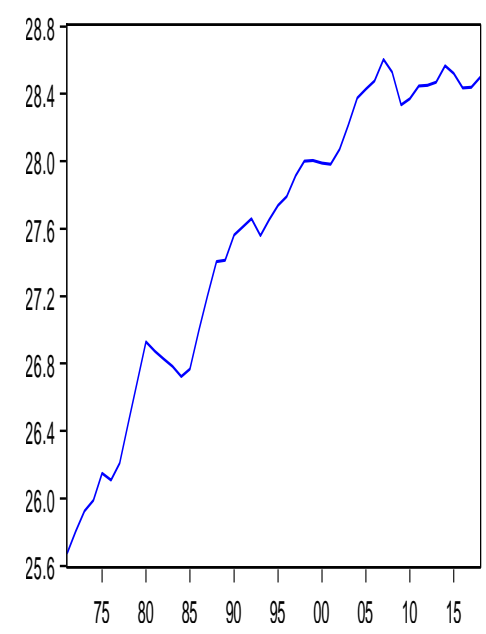




\section{Şekil 3: Ülkelerin Ticari Dışa Açıklığı}

LOGTO

Kanada

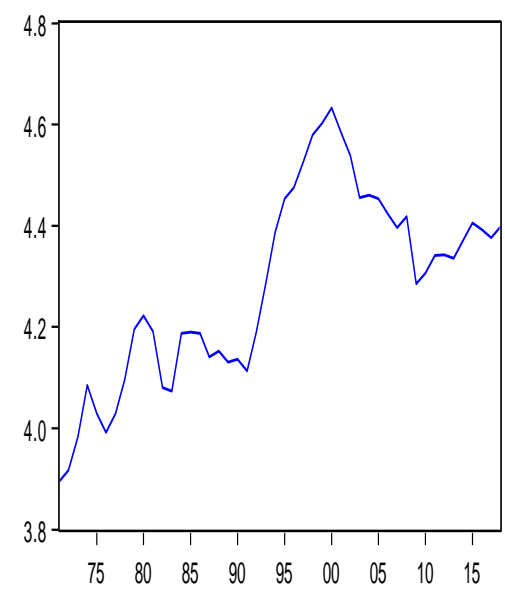

Italya

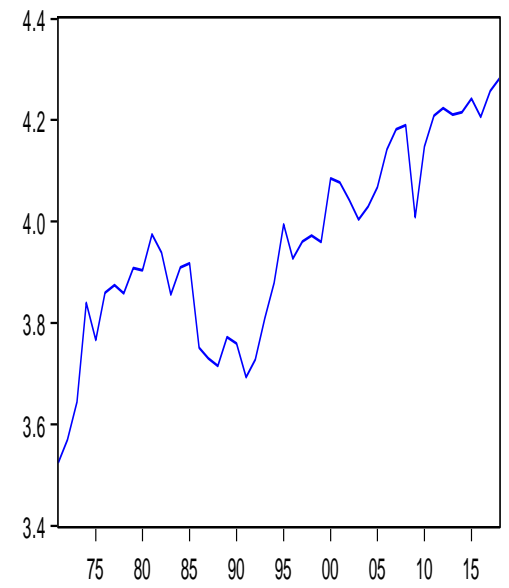

Ingiltere

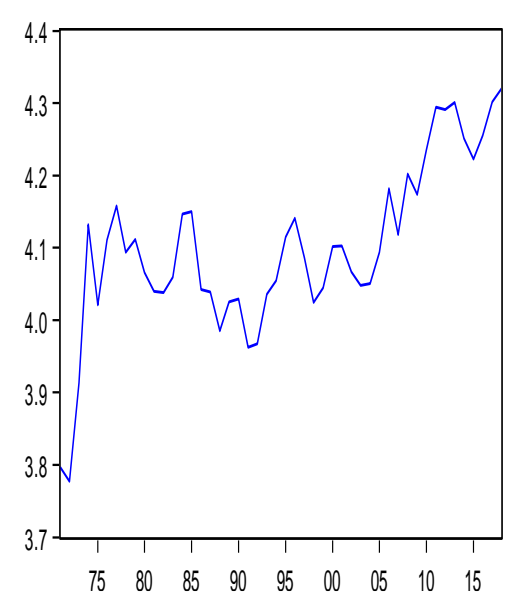

Almanya

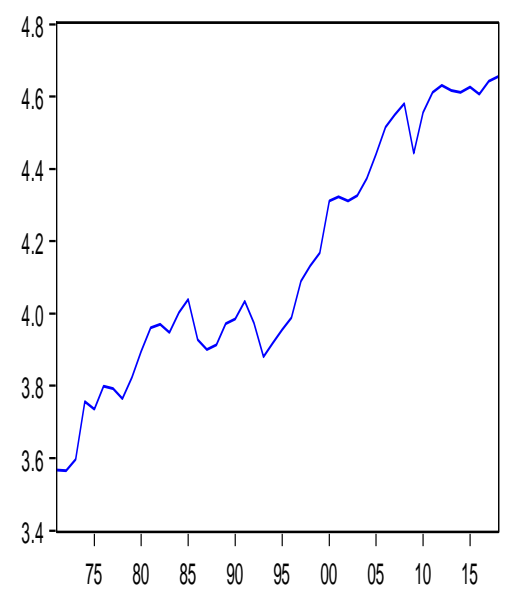

Japonya

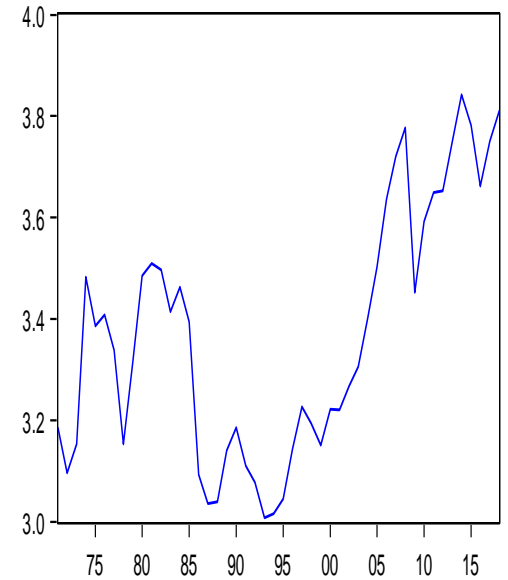

Fransa

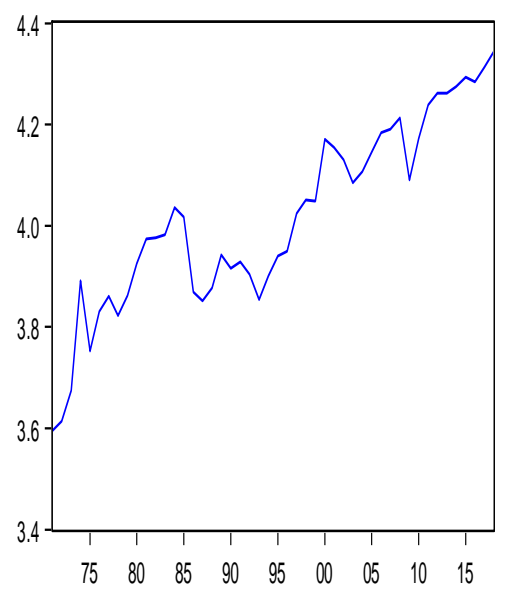

ABD

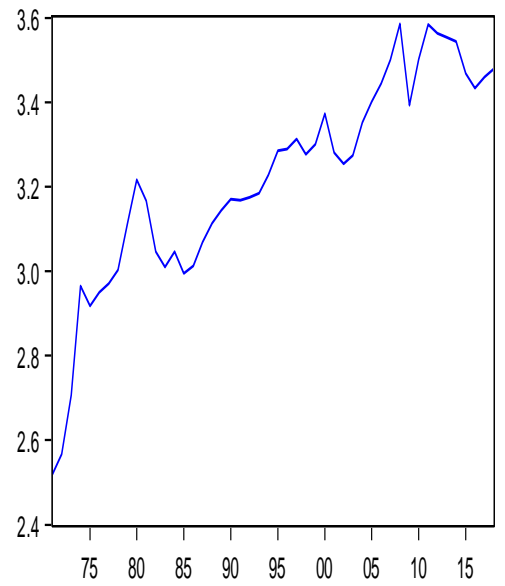




\section{Şekil 4: Ülkelerin Finansal Dışa Açıklığı}

LOGFO
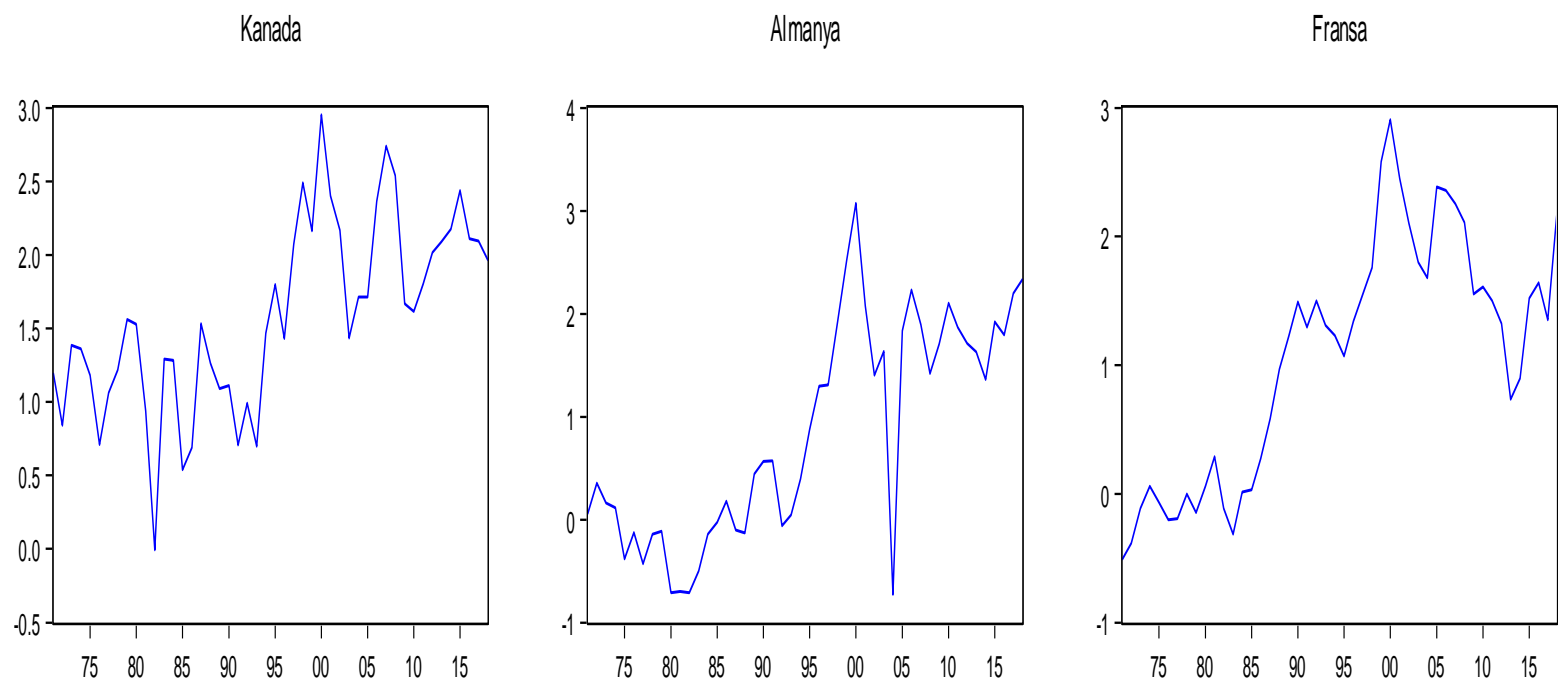

Italya

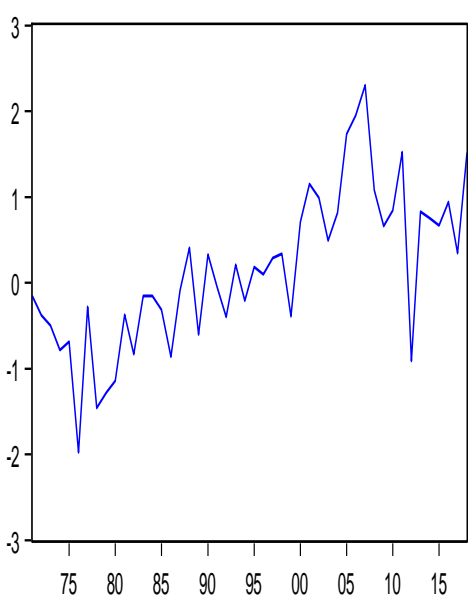

Japonya

$A B D$
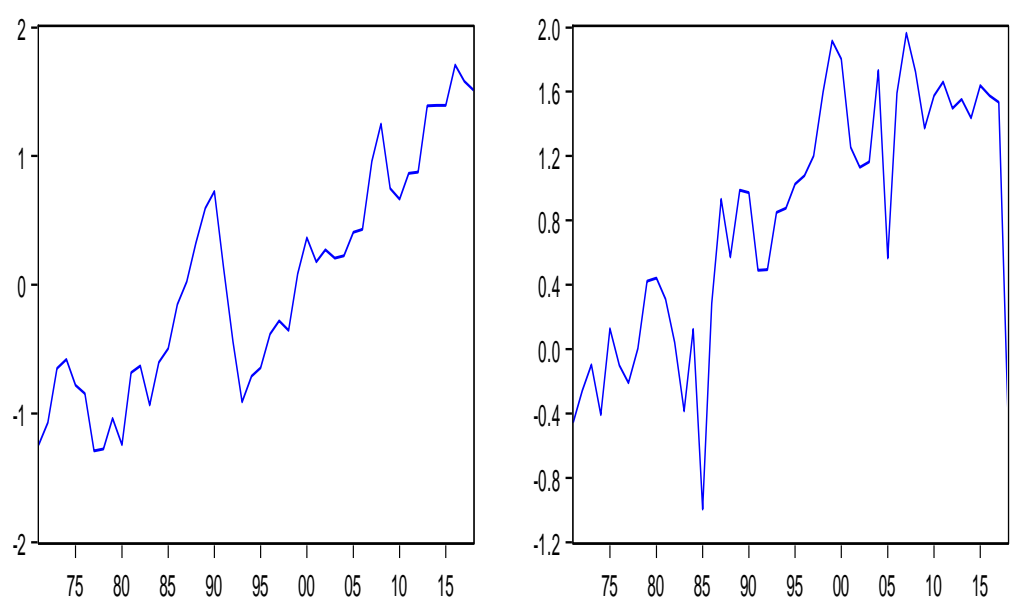

Ingiltere

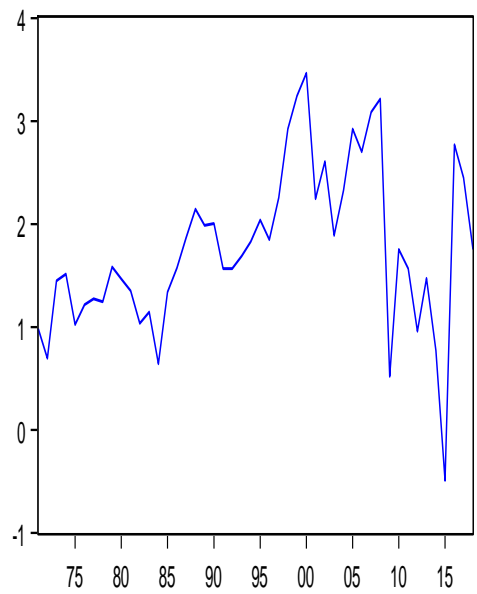


Tablo 3: Değişkenlerin Korelasyon Matrisi

\begin{tabular}{|c|c|c|c|}
\hline & LOGGDP & LOGTO & LOGFO \\
\hline LOGGDP & 1 & & \\
\hline LOGTO & -0.257 & 1 & 1 \\
\hline LOGFO & 0.266 & 0.551 & \\
\hline
\end{tabular}

Değişkenlere ait tanımlayıcı korelasyon matrisi Tablo 3'te gösterilmektedir. Gelirle ticari açıklık arasında istatistiki olarak negatif korelasyon varken, gelirle finansal açıklık değişkenleri arasında istatistiki olarak pozitif korelasyon vardır. Açıklayıcı değişkenler olan ticari dışa açıklık ile finansal dışa açıklık arasında pozitif korelasyon bulunmaktadır. Ayrıca korelasyon matrisi sonuçları açıklayıcı değişkenler arasında yüksek korelasyonun olmadığını ve buda çoklu doğrusal bağlantı probleminin olmadığı göstermektedir.

Tanımlayıcı istatistiklerin ardından, G7 ülkelerindeki büyüme, ticari dışa açılık ve finansal dışa açıklık arasındaki ilişki panel veri analizi ile yapılacağından, ilk olarak değişkenlerin durağanlık araştırması yapılmalıdır. Değişkenlerin durağanlık araştırmasının yapılabilmesi için ise ilk adım diye nitelendirebilecek yatay kesit bağımlılığının sınanması gerekmektedir. Panelin zaman boyutu yatay kesit boyutundan büyük olduğunda $(\mathrm{T}>\mathrm{N})$ Breusch ve Pagan (1980) CD-LM testi, zaman boyutunun yatay kesit boyutundan küçük olduğu durumlarda $(\mathrm{T}<\mathrm{N})$ ise Pesaran (2004) CD-LM testi kullanılabilmektedir. Bu çalışmada, $\mathrm{T}=50, \mathrm{~N}=7$ ve $(\mathrm{T}>\mathrm{N}$ ) olduğu için CD-LM testi referans alınmalıdır. Pesaran ve Yamagata (2008) tarafından geliştirilen delta testi ile de modeldeki sabit terimin ve modeldeki her değişkenin eğim katsayısının her ülke için homojen olarak dağıtılıp dağıtılmadı̆̆ı; Homojenlik sınanması yapılmaktadır. Yatay kesit bağımlılık ile homojenlik testlerine ait sonuçlar Tablo 4’te gösterilmiştir.

Tablo 4: Modelde Yatay Kesit Bağımlılı̆ı ve Homojenlik Test Sonuçları

\begin{tabular}{|c|c|c|}
\hline \multicolumn{3}{|c|}{ Yatay Kesit Bağımlılığı } \\
\hline Test & İstatistik & Olasilık \\
\hline Breusch-Pagan LM & 712.8112 & 0.076 \\
\hline Peseran Scaled LM & 106.7488 & 0.406 \\
\hline Pesaran CD & 26.66529 & 0.208 \\
\hline \multicolumn{3}{|c|}{ Homojenlik } \\
\hline Delta_tilte & -0.624 & 0.886 \\
\hline
\end{tabular}

Tablo 4'te yer alan test sonuçlarına göre, modelde yatay kesit bağımlılı̆̆ 1 yoktur ve homojenlik test sonuçlarına göre de eğim parametrelerinin homojendir. Aslında bu sonuçlar durağanlık sınaması için, birinci nesil mi yoksa ikinci nesil testlerle mi sınamanın doğru olacağına karar vermeye yaramaktadır. Sonuçlar birinci nesil birim kök testleri ile analize devam edilmesi gerektiğini göstermektedir. Panel veri setinde yatay kesit bağımlılığı varlığı reddedilirse, Levin, Lin ve Chu, (2002), Im, Pesaran ve Shin (2003), ADF-Fisher Ki-Kare (Maddala ve Wu, 1999), PP-Fisher Ki-Kare (Choi, 2001) gibi 1. nesil durağanlık testleri kullanılabilir. Durağanlık testlerindeki amaç, ilişkinin gerçek olup olmadığının araştırılmasıdır. Şöyle ki; değişkenlere ait serilerde eğer trend bulunuyorsa o zaman ilişki gerçek değil, sahte regresyon şeklinde kendini gösterir. Bu nedenle değişkenlerin durağanlıklarının incelenmesi gerekmekte ve bu inceleme de panel durağanlık (birim kök) testleri ile yapılmaktadır (Tarı; 2016:382).

Tablo 5: Panel Birim Kök Test Sonuçları

\begin{tabular}{|c|c|c|c|c|c|c|}
\hline \multicolumn{7}{|c|}{ DÜZEY } \\
\hline & Sabitli Trendsiz & & Sabitli Trendli & & Sabitsiz Trendsiz & \\
\hline & İstatistik & Prob. & İstatistik & Prob. & İstatistik & Prob. \\
\hline Levine, Lin ve Chu t & -6.77695 & 0.0000 & -2.07678 & 0.0189 & 5.99788 & 1.0000 \\
\hline Breitung t-stat & --- & -- & 2.98830 & 0.9986 & -- & -- \\
\hline Im, Pesaran and Shin W-stat & -3.08581 & 0.0010 & 0.13065 & 0.5520 & -- & -- \\
\hline ADF - Fisher Chi-square & 33.7572 & 0.0022 & 10.7966 & 0.7019 & 0.13067 & 1.0000 \\
\hline PP - Fisher Chi-square & 90.8391 & 0.0000 & 9.16401 & 0.8204 & 0.01163 & 1.0000 \\
\hline
\end{tabular}




\begin{tabular}{|c|c|c|c|c|c|c|}
\hline \multicolumn{7}{|c|}{ FO } \\
\hline & Sabitli Trendsiz & & Sabitli Trendli & & Sabitsiz Trendsiz & \\
\hline & İstatistik & Prob. & İstatistik & Prob. & İstatistik & Prob. \\
\hline Levine, Lin ve Chu t & -0.81268 & 0.2082 & -0.85822 & 0.1954 & -1.84270 & 0.0327 \\
\hline Breitung t-stat & -- & -- & -1.95222 & 0.0255 & -- & -- \\
\hline Im, Pesaran and Shin W-stat & -1.07497 & 0.1412 & -2.58960 & 0.0048 & -- & -- \\
\hline ADF - Fisher Chi-square & 17.9253 & 0.2102 & 28.7250 & 0.0114 & 16.4977 & 0.2839 \\
\hline PP - Fisher Chi-square & 27.9556 & 0.0144 & 47.4309 & 0.0000 & 23.1825 & 0.0574 \\
\hline \multicolumn{7}{|c|}{ TO } \\
\hline & Sabitli Trendsiz & & Sabitli Trendli & & Sabitsiz Trendsiz & \\
\hline & İstatistik & Prob. & İstatistik & Prob. & İstatistik & Prob. \\
\hline Levine, Lin ve Chu t & -2.35517 & 0.0093 & -1.29377 & 0.0979 & 3.83108 & 0.9999 \\
\hline Breitung t-stat & -- & -- & -1.72319 & 0.0424 & -- & -- \\
\hline Im, Pesaran and Shin W-stat & -1.13843 & 0.1275 & -2.31870 & 0.0102 & -- & -- \\
\hline ADF - Fisher Chi-square & 18.7679 & 0.1740 & 29.1037 & 0.0101 & 0.79749 & 1.0000 \\
\hline PP - Fisher Chi-square & 16.8273 & 0.2655 & 21.9466 & 0.0797 & 0.53750 & 1.0000 \\
\hline \multicolumn{7}{|c|}{ FARK } \\
\hline \multicolumn{7}{|c|}{ GDP } \\
\hline & Sabitli Trendsiz & & Sabitli Trendli & & Sabitsiz Trendsiz & \\
\hline & İstatistik & Prob. & İstatistik & Prob. & İstatistik & Prob. \\
\hline Levin, Lin \& Chu t* & -9.94149 & 0.0000 & -11.4552 & 0.0000 & -7.12200 & 0.0000 \\
\hline Breitung t-stat & - & --- & -8.61084 & 0.0000 & -- & -- \\
\hline Im, Pesaran and Shin W-stat & -7.80792 & 0.0000 & -8.47970 & 0.0000 & -- & -- \\
\hline ADF - Fisher Chi-square & 86.9021 & 0.0000 & 88.7153 & 0.0000 & 92.7169 & 0.0000 \\
\hline PP - Fisher Chi-square & 99.8059 & 0.0000 & 101.768 & 0.0000 & 105.549 & 0.0000 \\
\hline \multicolumn{7}{|c|}{ FO } \\
\hline & Sabitli Trendsiz & & Sabitli Trendli & & Sabitsiz Trendsiz & \\
\hline & İstatistik & Prob. & İstatistik & Prob. & İstatistik & Prob. \\
\hline Levin, Lin \& Chu t* & -9.84905 & 0.0000 & -8.63296 & 0.0000 & -15.3378 & 0.0000 \\
\hline Breitung t-stat & --- & - & -2.58623 & 0.0049 & -- & -- \\
\hline Im, Pesaran and Shin W-stat & -13.5171 & 0.0000 & -12.4446 & 0.0000 & -- & -- \\
\hline ADF - Fisher Chi-square & 168.791 & 0.0000 & 141.957 & 0.0000 & 267.703 & 0.0000 \\
\hline PP - Fisher Chi-square & 239.105 & 0.0000 & 618.816 & 0.0000 & 1020.72 & 0.0000 \\
\hline \multicolumn{7}{|c|}{ TO } \\
\hline & Sabitli Trendsiz & & Sabitli Trendli & & Sabitsiz Trendsiz & \\
\hline & İstatistik & Prob. & İstatistik & Prob. & İstatistik & Prob. \\
\hline Levin, Lin \& Chu t* & -11.4840 & 0.0000 & -10.7194 & 0.0000 & -13.0277 & 0.0000 \\
\hline Breitung t-stat & -- & -- & -11.7730 & 0.0000 & -- & -- \\
\hline Im, Pesaran and Shin W-stat & -11.3172 & 0.0000 & -10.1521 & 0.0000 & -- & -- \\
\hline ADF - Fisher Chi-square & 136.935 & 0.0000 & 109.899 & 0.0000 & 172.136 & 0.0000 \\
\hline PP - Fisher Chi-square & 197.175 & 0.0000 & 173.203 & 0.0000 & 282.197 & 0.0000 \\
\hline
\end{tabular}

Durağanlık test sonuçları Tablo 5'te gösterilmiştir. Hem bağımlı değişken olan GDP'nin hem bağımsız değişkenler olan ticari dışa açıklık ile finansal dışa açıklık değişkenlerin sabitli trendsiz, sabitli trendli ve sabitsiz trendsiz modellerindeki durağanlık sınamaları yapılmıştır. Bu testler genel olarak değerlendirildiğin de, hem bağımlı değişkenin hem de bağımsız değişkenlerin farkları alındıktan sonra durağanlaştıklarını söyleyebiliriz. Durağanlık testleri ile ilişkini sahte olmadığını gördükten sonra sıra modeli tahmin etmeye gelmiştir. Bunun için de böyle durumda en çok kullanılan modeller olan Sabit Etkiler Modeli ile Tesadüfi Etkiler Modeli yardımıyla tahmin sonuçları incelenip, değerlendirilerek model seçimi yapılacaktır. 
Tablo 6: Değişkenler için Sabit Etkiler Modeli

\begin{tabular}{|l|l|l|l|l|}
\hline \multicolumn{1}{|c|}{ Değişkenler } & \multicolumn{1}{c|}{ Katsayılar } & \multicolumn{1}{c|}{ Standart Hata } & \multicolumn{1}{c|}{ t-İstatistik } & Olasılık \\
\hline \multicolumn{5}{|c|}{ Bağımlı Değişken LOGGDP } \\
\hline C & 21.66171 & 0.654806 & 33.08113 & 0.0000 \\
\hline LOGFO & 0.397811 & 0.046005 & 8.647132 & 0.0000 \\
\hline LOGTO & 1.509517 & 0.175590 & 8.596820 & 0.0000 \\
\hline \multicolumn{7}{|c|}{ Tartılı İstatistik } & Bağımlı değişken ortalama & 27.85265 \\
\hline R-kare & 0.752759 & $\begin{array}{l}\text { Bağımlı değişken standart } \\
\text { sapma }\end{array}$ & 1.108544 \\
\hline Düzeltilmiş R-kare & 0.746710 & Hata kareler toplam & 101.7820 \\
\hline Açıklanan kareler toplam & 0.557907 & Durbin-Watson istatistik & 0.284781 \\
\hline F-istatistik & 124.4495 & & \\
\hline Olasılık (F-istatistik) & 0.000000 &
\end{tabular}

Tablo 6'da sabit etkiler modeli tahmin edilmiștir. Tahmin sonuçları incelendiğinde finansal açıklığın ve özellikle ticari dışa açıklı̆̆ın değişkeninin istatistiki olarak oldukça anlamlı olduğu ve işaretlerinin beklentilerle uyumlu olarak pozitif olduğu anlaşılmaktadır. Modelin determinasyon katsayısı yaklaşık yüzde yetmiş beş olarak bulunmuştur. Yani bağımsız değişkenler bağımlı değişkende ortaya çıkan değişmelerin yaklaşık yüzde yetmiş beşini açıklamaktadır. Bu modelde finansal açıklıktaki bir birimlik değişime karşılık GDP 0.39 birimlik bir değişmeye neden olurken, ticari dışa açıklıktaki bir birimlik değişime karşılık GDP 1.50 birimlik bir değişme ortaya çıkmaktadır.

Tablo 7: Değişkenler için Rassal Etkiler Modeli

\begin{tabular}{|c|c|c|c|c|}
\hline Değişkenler & Katsayılar & Standart Hata & t-İstatistik & Olasılık \\
\hline \multicolumn{5}{|c|}{ Bağımlı Değișken LOGGDP } \\
\hline $\mathrm{C}$ & 23.54600 & 0.629512 & 37.40356 & 0.0000 \\
\hline LOGFO & 0.455638 & 0.044920 & 10.14329 & 0.0000 \\
\hline LOGTO & 1.009163 & 0.164098 & 6.149763 & 0.0000 \\
\hline \multicolumn{5}{|c|}{ Tartılı İstatistik } \\
\hline R-kare & & 0.469647 & Bağımlı değişken ortalama & 5.568256 \\
\hline Düzeltilmiş R-kare & & 0.466462 & $\begin{array}{l}\text { Bağımlı değişken standart } \\
\text { sapma }\end{array}$ & 0.839502 \\
\hline Açıklanan kareler toplam & & 0.613203 & Hata kareler toplam & 125.2142 \\
\hline F-istatistik & & 147.4419 & Durbin-Watson istatistik & 0.247422 \\
\hline Olasılık (F-istatistik) & & 0.000000 & & \\
\hline
\end{tabular}

Yukarıda tablo 7'de rassal (tesadüfi) etkiler modeli tahmin edilmiştir. Tahmin sonuçlarına göre, hem sabit katsayısının hem de açıklayıcı değişkenlerin istatistiki açıdan oldukça anlamlı olduğu anlaşılmaktadır. Modelin belirlilik katsayısı yaklaşık olarak yüzde 47 olarak bulunmuştur. Diğer bir ifade ile açıklayıcı değişkenler açıklanan değişkendeki değişimlerin yaklaşık yüzde kırk yedisini açıklamaktadır. Bu modelde finansal açıklıktaki bir birimlik değişime karşılık GDP'de 0.45 birimlik bir değişime neden olurken, ticari dışa açıklıktaki bir birimlik değişime karşılık GDP'de 1.00 birimlik bir değişime neden olmaktadır.

Tablo 8: Model Belirleme: Değişen Varyans, Otokorelasyon ve Birimlerarası Korelasyon Testleri

\begin{tabular}{|l|c|c|}
\hline \multicolumn{1}{|c|}{ Test Özeti } & İstatistik & Olasılık \\
\hline Modified Wald Test & 361.63 & 0.0000 \\
\hline Wooldridge Test & 92.421 & 0.0000 \\
\hline Breusch-Pagan LM Test & 1008.000 & 0.0000 \\
\hline
\end{tabular}

Tablo 8'de değişen varyans sorunu için yapılan Modified Wald test sonuçları, modelde değişen varyans (heteroskedasite) sorununun olduğunu, otokorelasyon sorunu için yapılan Wooldridge test sonuçları, modelde otokorelasyon sorununun olduğunu, birimler arası korelasyon sorunu için yapılan Breusch-Pagan LM test sonuçları ise, modelde birimler arası korelasyon sorununun da olduğunu işaret etmektedir. 
Tablo 9: Model Belirleme: Hausman Testi

\begin{tabular}{|l|l|l|l|l|}
\hline Test Özeti & Ki-kare. istatistik & Ki-kare. d.f. & Olasılık \\
\hline Yatay-kesit rastsal & \multicolumn{2}{|c|}{2} & 0.0000 \\
\hline Yatay kesit rastsal etkiler test karşılaştırmaları: & \multicolumn{4}{|l|}{} \\
\hline Değişken & Sabit & Rastsal & Var & Olasılık \\
\hline LOGFO & 0.397811 & 0.455638 & 0.000099 & 0.0000 \\
\hline LOGTO & 1.509517 & 1.009163 & 0.003904 & 0.0000 \\
\hline
\end{tabular}

Tablo 9 model belirlemek için ise Hausman test sonuçlarını göstermektedir. Hausman test sonuçları, tesadüfi etkiler mi yoksa sabit etkiler modelinden hangisinin tercih edilmesi gerektiğini gösterir. Sonuçlarına bakıldığında, sabit etkiler modelini kullanmamız gerektiği görülmektedir. Bu durumda verilerimiz için en uygun modelin sabit etkiler modeli olduğu sonucuna ulaşılmaktadır. Ayrıca model belirlenirken, modelde değişen varyans sorununun, otokorelasyon sorununun ve birimler arası korelasyon sorununun da olduğunu da göz önüne alan tahminleme yapılmalıdır.

\section{SONUÇ VE DEĞERLENDİRME}

Globalleşme ülkeler arası entegrasyonun doğmasına neden olmuş böylece ülkeler kural ve kurumlarını baştan dizayn ederek ekonomilerine yön vermişlerdir. Serbestleşme ilk olarak ticari alanda başlayıp daha sonra finansal boyuta ulaşmıştır. Ticari açıklık; dış ticaret politikası, liberalizasyon veya serbestleşme gibi kavramlarla iç içe kullanılmaktadır. Finansal dışa açıklık; dünya ekonomisinin finansal açıdan birbirine bağımlılığını belirttiğinden dolayı sermaye giriş ve çıkışları ile birlikte ifade edilmektedir. Bu çalışmada küreselleşme sürecinin temel iki dayanağı olan ticari ve finansal serbestleşmenin G7 ülkeleri özelinde, ülkelerin büyümelerine olan etkileri incelenmiştir. 1970-2020 y1lları arasında, 50 y1llık dönemde yıllık verilerle, panel veri analizi yapılmıştır. Analiz yapılırken önce, yatay kesit bağımlılı̆̆ 1 ve homojenlik sınaması yapılmış; yatay kesit bağımlılığının olmadığı ve eğim parametrelerinin homojen olduğu görülmüştür. Bu sonuçlar durağanlık analizi için birinci nesil birim kök testleri ile analize devam edilmesi gerektiğini göstermiş ve bu testler, genel olarak değerlendirildiğin de, hem bağımlı değişkenin hem de bağımsız değişkenlerin farkları alındıktan sonra durağanlaştıkları göstermiştir. Durağanlık testleri ile ilişkinin sahte olmadığı tespit edildikten sonra model sabit etkiler ve tesadüfi etkiler modeli ile tahmin edilmiştir. Tahmin sonuçları en uygun modelin tespiti için Hausman testi ile karşılaştırılmış ve sabit etkiler modelini kullanmak gerektiği görülmüştür. Ayrıca sabit etkiler ile tahmin yapılırken, modelde değişen varyans, otokorelasyon ve birimler arası korelasyon sorununun da olduğunu da göz önüne alarak tahminleme yapılmıştır. Sabit etkiler modelini tahmin sonuçları finansal açıklığın ve ticari dışa açıklığın büyüme üzerinde istatistiki olarak oldukça anlamlı olduğunu göstermektedir. Bu sonuç; Lee ve Shin (2008)'in finansal serbestleşmenin büyüme üzerinde pozitif etkisi vardır sonucuyla, Chang, Kaltani ve Loayza (2009)'un ticari dışa açıklık büyümeyle ilişkilidir sonucuyla, Chang ve Mendy (2012)'nin ticari açıklı büyümeyi pozitif yönde etkiler sonucuyla, Kennedy (2013)'ün finansal açıklık ekonomik büyümeyi pozitif yönde etkiler sonucuyla, Dao (2014)'ün ticari açıklık büyümeyi pozitif yönde etkiler sonucuyla, Idris, Yusop ve Habibullah (2016)'nın ticari dışa açıklık, ekonomik büyümeyi pozitif olarak etkiler sonucuyla uyum göstermektedir. 


\section{KAYNAKÇA}

Abbes, S. M., Mostefa, B., Seghir, G. M. ve Zakarya, G. Y. (2015). Causal Interaction between FDI, and Economic Growth: Evidence from Dynamic Panel Co-Integration. Procedia Economics and Finance, 23, 276-290.

Aizenman, J. (2008). On the Hidden Links Between Financial and Trade Opening. Journal of International Money and Finance, 27(3), 372-386.

Bader, S. ve Qarn, A. (2006). Financial Development and Economic Growth Nexus: Time Series Evidence From Middle Eastern and North African Countries, MPRA Discussion Paper 972.

Bourdon, M., Mouél, C. ve Vij11, M. (2013). The Relationship between Trade Openness and Aconomic Growtrh: Some New Insights on The Openness Measurement Issue. Hall- Archives, Ouvertes. 1-18.

Breusch, T. S. ve Pagan, A. R. (1980). The Lagrange Multiplier Test and Its Applications to Model Specification in Econometrics. Review of Economic Studies, 47(1), 239-253.

Chang, C.-C. ve Mendy, M. (2012). Economic Growth and Openness in Africa: What is the Empirical Relationship?. Applied Economics Letters, 19(18), 1903-1907.

Chang, R., Kaltani, L. ve Loayza, N. V. (2009). Openness Can Be Good for GROWTH: The Role of Policy Complementarities. Journal of Development Economics, 90(1), 33-49.

Cho1, I. (2001). Unit Root Test for Panel Data. Journal of International Money and Finance, 20(2), $249-272$.

Çeştepe, H., Yıldırım, E. ve Özbek, Z. (2018). Ticari ve Finansal Açıklığın Ekonomik Büyüme Üzerine Etkisi: Türkiye’ye İlişkin Ampirik Kanıtlar. Bolu Abant İzzet Baysal Üniversitesi Sosyal Bilimler Enstitüsü Dergisi, 18(4), 1-17.

Dağdelen, İ. (2004). Liberalizasyon. Uluslararası İnsan Bilimleri Dergisi, 1(1), 1-66.

Danışoğlu, A. Ç. (2004). Finansal Gelişme ve İktisadi Büyüme İlişkisi: Türkiye Örneği. Yönetim Dergisi, 49, 19-29.

Dao, A. T. (2014). Trade Openness and Economic Growth. Mark A. Israel '91 Endowed Summer Research Fund in Economics 2, 1-29.

Ericsson, J. ve Irandoust, M. (2001). On the Causality between Foreign Direct Investment and Output: A Comparative Study. International Trade Journal, 15, 1-26.

Giddens, A. (2000). Üçüncü Yol: Sosyal Demokrasinin Yeniden Dirilişi. M. Özay (çev.). İstanbul: Birey Yayıncılık (orijinal bask1 tarihi 1999).

Gries, T. ve Redlin, M. (2012). Trade Openness and Economic Growth: A Panel Causality Analysis. CIE Working Papers No. 52. Center for International Economics, University of Paderborn.

Idris, J., Yusop, Z. ve Habibullah, M. S. (2016). Trade Opennes and Economic Growth: A Causality test in Panel Perspective. International Journal of Business and Society, 17(2), 281-290.

Im, K. S., Peseran, M. H. ve Shin, Y. (2003). Testing for Unit Roots in Heterogeneous Panels. Journal of Econometrics, 115(1), 53-74.

Kennedy A. (2013). Financial Openness and Growth: 2000-2010. Volume 6, Pepperdine Policy Review Article 4, 5-27.

Korkmaz, T., Çevik, E. ve Birkan, E. (2010). Finansal Dışa Açıklığın Ekonomik Büyüme ve Finansal Krizler Üzerindeki Etkisi: Türkiye Örneği. Journal of Yaşar University, 5(17), 2821-2831.

Lee, I. ve Shın, J.-H. (2008). Financial Liberalization, Crises, and Economic Growth. Asian Economic Papers. 7(1), 106115.

Levin, A., Lin, C.-F. ve Chu, C.-S. J. (2002). Unit Root Tests in Panel Data: Asymptotic and Finite-Sample Properties. Journal of Econometrics, 108(1), 1-24.

Lu, D. ve Liu, E. (2020). In Search of Currency İnternationalisation: A Perspective from Financial Openness, Economic and Political Studies, 8(3), 312-330.

Maddala, G. S. ve Wu, S. (1999). A Comparative Study of Unit Root Tests with Panel Data and a New Simple Test. Oxford Bulletin of Economics and Statistics, 61(1), 631-652.

McKinnon, R. (1973). Money and Capital in Economic Development. Washington, DC: The Brookings Institution.

Özyıldız, T, ve Dineri, E. (2020). BRICS Ülkelerinde Para Arzı, Finansal ve Ticari Açıklığın Ekonomik Büyüme Üzerindeki Etkisi. Recep Tayyip Erdoğan Üniversitesi Sosyal Bilimler Dergisi, 6 (11), 30-54.

Pesaran, M. H. (2004). General Diagnostic Tests for Cross Section Dependence in Panels. University of Cambridge Working Paper, 0435.

Peseran, M. H., Ullah, A. ve Yamagata, T. (2008). A Bias-Adjusted LM Test of Error Cross-Section İndependence. Econometrics Journal, 11, 105-127.

Saçık, S. (2009). Büyümenin Bir Kaynağı Olarak Ticari Dışa Açıklık. Sosyal Ekonomik Araştırmalar Dergisi, 9(17), 525548.

Shaw, E. S. (1973). Financial Deeping in Economic Development. Cambridge: Harvard University Press.

Silajdzic, S. ve Mehic, E. (2017). Trade Openness and Economic Growth: Emprical Evidence from Transisitons Economies. Menagement International Conference, Italy, 24-27 May, 581-594.

Tarı, R. (2016). Ekonometri. İstanbul: Kocaeli Üniversitesi Vakfi Yayınlar1.

Tornell, A., Westermann, F. ve Martinez, L. (2004). The Positive Link Between Financial Liberalization Growth and Crises. NBER Working Papers. No. 10293.

Ümit, A. (2016). Türkiye'de Ticari Açıklık, Finansal Açıklık ve Ekonomik Büyüme Arasındaki İlişkiler: Sınır Testi Yaklaşımı. Niğde Üniversitesi İktisadi ve İdari Bilimler Fakültesi Dergisi, 9(1), 255-272. 
World Development Indicators (WDI) Online Veritabanı. https://databank.worldbank.org/data/reports. aspx ? source $=$ World-Development-Indicators.

Yapraklı, S. (2007). Ticari ve Finansal Dışa Açıklık ile Ekonomik Büyüme Arasındaki İlişki: Türkiye Üzerine Bir Uygulama. İstanbul Üniversitesi İktisat Fakültesi Ekonometri ve İstatistik Dergisi, 5, 67-89.

Zeren, F. ve Ari, A. (2013). Trade Openness and Economic Growth: A Panel Causality Test. International Journal of Business and Social Science, 4(9), 317-324. 